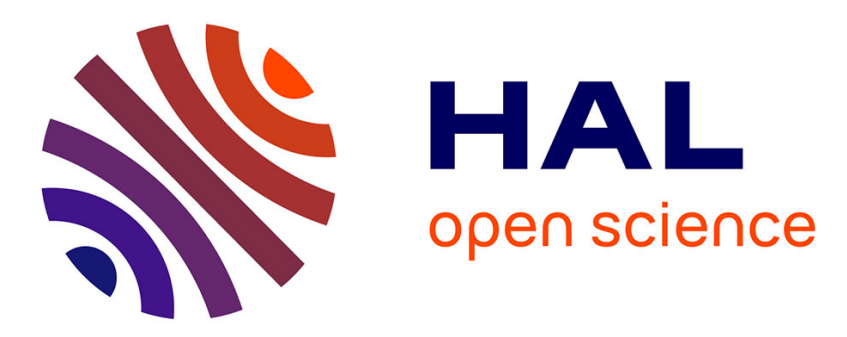

\title{
Predicting in vivo gene expression in macrophages after exposure to benzo(a)pyrene based on in vitro assays and toxicokinetic/toxicodynamic models
}

Alexandre R.R. Pery, Céline Brochot, Sophie Desmots, Magali Boize, Lydie Sparfel, Olivier Fardel

\section{To cite this version:}

Alexandre R.R. Pery, Céline Brochot, Sophie Desmots, Magali Boize, Lydie Sparfel, et al.. Predicting in vivo gene expression in macrophages after exposure to benzo(a)pyrene based on in vitro assays and toxicokinetic/toxicodynamic models. Toxicology Letters, 2011, 201 (1), pp.8-14. 10.1016/j.toxlet.2010.11.017 . hal-00873317

\section{HAL Id: hal-00873317 https://hal.science/hal-00873317}

Submitted on 29 Apr 2014

HAL is a multi-disciplinary open access archive for the deposit and dissemination of scientific research documents, whether they are published or not. The documents may come from teaching and research institutions in France or abroad, or from public or private research centers.
L'archive ouverte pluridisciplinaire HAL, est destinée au dépôt et à la diffusion de documents scientifiques de niveau recherche, publiés ou non, émanant des établissements d'enseignement et de recherche français ou étrangers, des laboratoires publics ou privés. 


\title{
Predicting in vivo gene expression in macrophages after exposure to benzo(a)pyrene based on in vitro assays and toxicokinetic/toxicodynamic models
}

\author{
Alexandre R.R. Péry ${ }^{\mathrm{a},}{ }^{,}$, Céline Brochot ${ }^{\mathrm{a}}$, Sophie Desmots ${ }^{\mathrm{b}}$, Magali Boize ${ }^{\mathrm{c}}$, Lydie Sparfel $^{\mathrm{d}}$, \\ Olivier Fardel ${ }^{\mathrm{d}}$ \\ ${ }^{a}$ Unité « Modèles pour l'écotoxicologie et la toxicologie » (METO), INERIS, parc Alata \\ BP2, 60550 Verneuil-en-Halatte, France. \\ ${ }^{\mathrm{b}}$ Unité « Toxicologie expérimentale » (TOXI), INERIS, parc Alata BP2, 60550 Verneuil-en- \\ Halatte, France. \\ ${ }^{\mathrm{c}}$ Service des études médicales EDF, 22-28 rue Joubert, 75009 Paris, France. \\ ${ }^{\text {d EA }} 4427$ SeRAIC, Institut de Recherche sur la Santé, l'Environnement et le Travail, \\ Université de Rennes 1, 2 Avenue du Pr Léon Bernard, 35043 Rennes, France. \\ * Corresponding author at: INERIS, parc Alata BP2, 60550 Verneuil-en-Halatte, France. Tel: \\ +33 3445561 26. E-mail adress: alexandre.pery@ineris.fr.
}




\begin{abstract}
Predictive toxicology aims at developing methodologies to relate the results obtained from in vitro experiments to in vivo exposure. In the case of polycyclic aromatic hydrocarbons (PAH), a substantial amount of knowledge on effects and modes of action has been recently obtained from in vitro studies of gene expression. In the current study, we built a physiologically based toxicokinetic (PBTK) model to relate in vivo and in vitro gene expression in case of exposure to benzo $(a)$ pyrene $(\mathrm{B} a \mathrm{P})$, a referent $\mathrm{PAH}$. This model was calibrated with two toxicokinetic datasets obtained on rats exposed either through intratracheal instillation or through intravenous administration and on an in vitro degradation study. A good agreement was obtained between the model's predictions and the concentrations measured in target organs, such as liver and lungs. Our model was able to relate correctly the gene expression for two genes targeted by PAHs, measured in vitro on primary human macrophages and in vivo in rat macrophages after exposure to $\mathrm{B} a \mathrm{P}$. Combining in vitro studies and PBTK modeling is promising for PAH risk assessment, especially for mixtures which are more efficiently studied in vitro than in vivo.
\end{abstract}

Key-words: PBPK, model calibration, $\mathrm{B} a \mathrm{P}$, gene expression, vitro-vivo extrapolation. 


\section{Introduction}

Polycyclic aromatic hydrocarbons (PAHs) exert a variety of toxic responses toward human health, including carcinogenic, immunotoxic, neurodevelopmental and cardiovascular effects, and are likely to contribute to smoking-related diseases (Sorensen et al., 2003 ; Slotkin and Seidler, 2009). PAHs are products of incomplete combustion of fossil fuels, wood, and other organic materials at temperatures between 300 and $600{ }^{\circ} \mathrm{C}$, and, as such, are ubiquitous in the environment. $\operatorname{Benzo}(a)$ pyrene $(\mathrm{B} a \mathrm{P})$, a five ring $\mathrm{PAH}$, is usually used as a marker of exposure and effects of complex mixtures including PAHs, either directly (as a surrogate for the PAH fraction of complex mixtures) or using toxicity equivalency factors to relate the toxicity of each $\mathrm{PAH}$ to the one of $\mathrm{B} a \mathrm{P}$ (Pufulete et al., 2004). In particular, $\mathrm{B} a \mathrm{P}$ is the reference compound for lung cancer risk assessment relative to exposure to environmental PAHs (Vyskocil et al., 2004).

A substantial amount of the knowledge on $\mathrm{B} a \mathrm{P}$ mode of action and effects has been obtained in vitro. Human hazard assessment for regulatory purposes is still mainly carried out using animal studies, and seldom accounts for ongoing innovations in the field of in vitro toxicology. However, obtaining relevant dose-response relationships for systemic endpoints, like reproductive toxicity or cancer, based on extrapolated in vitro data, is a great challenge to avoid expensive and lengthy in vivo testing. It is envisioned by toxicologists that future risk assessment would focus on avoiding significant perturbations in toxicity pathways through in vitro toxicity pathway assays on human cells or cell lines (Krewski et al., 2010). To integrate the in vitro results into quantitative in vivo risk assessment, these assays would be analyzed with computational systems biology models to derive an in vitro dose-response, which would then be extrapolated in vivo based on toxicokinetic of the chemicals in the organism of interest. For instance, Verwei et al. (2006) showed that the combination of in vitro tests for embryotoxicity with toxicokinetic modeling permits relevant predictions of in vivo developmental effects in rodents. Although combining in vitro and in silico techniques appears as a promising alternative test method for risk assessment, such methodology is still rarely applied.

Macrophages are target cell types for PAHs, with consequences related to immune response, inflammatory pathways, tissue injuries, atherosclerosis, monocyte differentiation and lipid accumulation. In order to identify early markers of toxicity that may potentially be linked with the occurrence of pathologies, the expression of the genes of macrophages has been studied after exposures to different doses of $\mathrm{B} a \mathrm{P}$. Expression of many genes, including 
interleukin (IL)-1 $\beta$, IL-8, tumor necrosis factor (TNF)- $\alpha$, NADPH oxidase subunit gene neutrophil cytosolic factor 1 (NCF1), and CC-chemokine ligand 1, was found up-regulated in human blood monocyte-derived macrophages or rodent alveolar macrophages (Lecureur et al., 2005 ; N’Diaye et al., 2006 ; Podechard et al., 2008 ; Pinel-Marie et al., 2009). The nature of molecular $\mathrm{B} a \mathrm{P}$ target genes in primary human macrophages has recently been characterized (Sparfel et al., 2010). IL-1 $\beta$ and the aryl hydrocarbon receptor (AhR) repressor were confirmed as targets, whereas new targets were found, including the chemokine receptor CXCR5, the G protein coupled receptor 35 (GPR35), and the Ras regulator RASAL1.

Physiologically based toxicokinetic (PBTK) models are particularly relevant to relate in vitro and in vivo responses, since the modeling of the toxicokinetic of chemicals is based on the physiology of the organism and that the internal dosimetry in the target tissues may be assessed. Few PBTK models for $\mathrm{B} a \mathrm{P}$ have been already developed in rats (Roth and Vinegar, 1990 ; Zeilmaker et al., 1999 ; Moir, 1999). These models suffer from different problems which make questionable their use in lung toxicity assessment. All of these models were developed with toxicokinetic data of $\mathrm{B} a \mathrm{P}$ in different organs/tissues after an intravenous administration. Even if these data described the distribution of $\mathrm{B} a \mathrm{P}$ into the tissues from blood circulation, they were unable to inform the absorption of $\mathrm{B} a \mathrm{P}$ through the lungs, which is the major route of exposure of PAHs. The kinetics of $\mathrm{B} a \mathrm{P}$ in lungs was also not well reproduced by these models. Either lungs were not described by the model (Zeilmaker et al., 1999) or the partition coefficient between lungs and blood, estimated through QSAR modeling (Chiang and Liao, 2006), equilibrium dialysis experiment (Moir, 1999) or interactive adjustment (Roth and Vinegar, 1990), was low compared to actual concentration data in lungs and blood (Schlede et al., 1970 ; Weyand and Bevan, 1986). These models would consequently underestimate $\mathrm{B} a \mathrm{P}$ lung concentration. There is therefore a need to improve the modeling of the lungs toxicokinetics.

In this paper, we propose to combine the toxicokinetic modeling of $\mathrm{B} a \mathrm{P}$ in vivo and doseresponse relationships derived in vitro to assess the effects of $\mathrm{BaP}$ on the expression of two target genes for PAHS, IL-1 $\beta$ and NCF1. First experimental in vitro assays on macrophages will be conducted to construct dose-response models for the expression of the two genes. Then a PBPK model for BaP in rats including the description of lungs will be calibrated with concentrations in different tissues after an intratracheal instillation (Weyand and Bevan, 1986) and an intravenous administration (Schlede et al., 1970). Intratracheal instillation is a useful and cost-effective procedure for addressing specific questions regarding the respiratory toxicity of chemicals and presents many advantages over inhalation (Driscoll et al., 2000): the 
actual dose delivered to the lungs can be assured, a range of doses can be introduced into the lungs within a short time, and exposure to the skin and pelt can be avoided. Once parameterized, the PBPK model will be linked to the dose-response relationships derived in vitro to extrapolate the in vitro responses to in vivo conditions. The prediction of the expression of the genes will then be compared to actual responses obtained from an exposure of rat to $\mathrm{B} a \mathrm{P}$. Our methodology is illustrated in Figure 1.

\section{Materials and methods}

\subsection{Toxicokinetics data in rats for $\mathrm{Ba} P$ and metabolites}

Two sets of toxicokinetic data were used. The first one, by Weyand and Bevan (1986), was obtained in Sprague-Dawley rats after an intratracheal instillation of $1 \mu \mathrm{g} / \mathrm{kg} \mathrm{B} a \mathrm{P}$. It has never been used for PBTK modeling. Concentrations of $\mathrm{B} a \mathrm{P}$ and metabolites were measured in lungs, liver, blood and intestine at different times from 5 to $360 \mathrm{~min}$ after instillation. Animals were maintained on a steep incline for 5-10 min following $\mathrm{B} a \mathrm{P}$ administration. It was not clear if this period was accounted for in calculating the time between administration and measurement. We consequently did not use the data at 5 and $10 \mathrm{~min}$ for the estimation of parameters to avoid the use of confounding measurements. These data are however presented in the figures from the result section.

We analyzed Weyand and Bevan dataset together with other existing and available data obtained in Sprague-Dawley rats after an intravenous administration of $10 \mu \mathrm{g} \mathrm{BaP}$ (Schlede et al., 1970). These data have previously been used in a PBTK modeling context, to compare with the outputs of a model in development (Roth and Vinegar, 1990). These data comprise lungs, liver, adipose tissues and blood $\mathrm{B} a \mathrm{P}$ concentrations at different times from 5 to 360 min. In addition to contributing to build a model robust enough to account for different exposure routes, the use of this second dataset was necessary to account for the kinetics in adipose tissues. These tissues store and release a substantial quantity of $\mathrm{B} a \mathrm{P}$ with an important influence on long-term kinetics.

\subsection{In vitro exposure of macrophages to $\mathrm{Ba} P$}

Peripheral blood mononuclear cells were obtained from blood donor buffy coats (kindly provided by the Etablissement Français du Sang, Rennes, France), through Ficoll (Life 
Technologies, Cergy-Pontoise, France) gradient centrifugation. After a selective 2-h step of adhesion, human adherent monocytes were cultured for 6 days in RPMI 1640 medium (Eurobio, Les Ulis, France), supplemented with 2 mM L-glutamine, 20 units/ml penicillin, 20 $\mu \mathrm{g} / \mathrm{ml}$ streptomycin and $10 \%$ decomplemented fetal bovine serum (Thermo Fischer Scientific, Perbio Science, Berbières, France), in the presence of 400 units/ml granulocyte macrophage-colony stimulating factor (Schering Plough, Lyon, France). Such a protocol permits to obtain pure macrophagic cultures, validated by analysis of the expression of the macrophagic marker CD71, with less than $1 \%$ of contaminating cells such as CD3- or CD19positive lymphocytes, as assessed by immunophenotyping (van Grevenynghe et al. 2004). Macrophagic cells were cultured in serum-free medium for $24 \mathrm{~h}$ prior to a $24-\mathrm{h}$ exposure to various increasing $\mathrm{B} a \mathrm{P}$ concentrations $(0-10 \mu \mathrm{M})$.

\subsection{Exposure of rats to $\mathrm{Ba} P$}

Male Sprague-Dawley rats were purchased from Charles River Laboratory (L'Abresle, France). They were maintained under standardized conditions (relative humidity $55 \pm 15 \%, 12-$ $\mathrm{h}$ day night cycle, room temperature $22 \pm 2^{\circ} \mathrm{C}$ ). Rats were exposed to $3 \mathrm{mg} / \mathrm{kg} \mathrm{B} a \mathrm{P}$ dissolved in $\mathrm{NaCl}$-bovine serum albumin by intratracheal instillation. Control rats received vehicle only. Twenty four hours after the instillation, animals were euthanized with a lethal dose of sodium pentobarbital (Ceva Santé Animale, France). After exsanguinations, bronchoalveolar lavages were performed and alveolar macrophages were collected. We did not observe alterations of the percentage of alveolar macrophages in bronchoalveolar lavages due to $\mathrm{B} a \mathrm{P}$ treatment (data not shown). The experimental protocol has been approved by the local ethical committee for animal research.

\subsection{RNA isolation and reverse transcription-real time quantitative PCR assay (RT-qPCR)}

Total RNA was isolated from macrophages using the TRIzol method (Invitrogen, CergyPontoise, France). Total RNA (1 $\mu \mathrm{g})$ was reverse-transcribed into cDNA using the RT Applied Biosystems kit (Foster City, CA). Quantitative PCR (qPCR) assays were next performed using the fluorescent dye SYBR Green methodology and an ABI Prism 7000 detector (Applied Biosystems). The gene specific primers were provided by Qiagen (Courtaboeuf, France). The specificity of each gene amplification was verified at the end of

qPCR reactions through analysis of dissociation curves of the PCR products. Amplification 
curves were analysed with ABI Prism 7000 SDS software using the comparative cycle threshold method. Relative quantification of the steady-state target mRNA levels was calculated after normalization of the total amount of cDNA tested to a $18 \mathrm{~S}$ mRNA endogenous reference.

\subsection{In vitro dose response modeling}

The Hill model was used to fit the dose-gene expression profile, as it has already been proposed by other authors (Varma et al., 2007). The Hill function we used has the general form:

$$
E=1+\left(E_{\max }-1\right) \frac{c^{n}}{c^{n}+c_{50}^{n}}
$$

where the baseline activity is 1 with no $\mathrm{B} a \mathrm{P}, E_{\max }$ is the maximum gene expression level, $c_{50}$ is the dose resulting in 50\% of the maximum increase in gene expression, $n$ is the Hill coefficient defining the shape of the dose-response curve and $c$ is the $\mathrm{B} a \mathrm{P}$ concentration. The model was fitted to the experimental in vitro gene expression using the least squares method with a prior normalization for each concentration by the standard error of the response to avoid overweighting high concentrations. Confidence intervals were calculated through data bootstrapping. The software R, version 2.7.1, was used (R Development Core Team, 2008).

\subsection{PBTK modeling}

Figure 2 presents a description of the PBTK model. The body is represented by lungs, fat, liver, richly perfused and slowly perfused tissues. The model is divided into two sub-models, one for $\mathrm{B} a \mathrm{P}$, and one for its metabolites, treated as a whole by assuming common kinetics for simplification. The sub-models are connected through liver metabolism. To describe $\mathrm{B} a \mathrm{P}$ kinetics, fat is separated between adipose tissues and blood in adipose tissues to account for diffusion in this compartment (Zeilmaker et al., 1999 ; Moir, 1999).

For metabolites, we assumed that adipose tissues, richly and slowly perfused tissues had the same partition coefficient with blood and that there was no diffusion limitation in adipose tissues. We assumed that only metabolites (and no parent compound) were found in the intestine as suggested by Weyand and Bevan, who found that less than $2 \%$ of intestinal content was $\mathrm{B} a \mathrm{P}$ after 60 and 360 min. 
The parameters of the model are presented in Table 1. The differential Equations 1-5 were used to calculate the change in amount of $\mathrm{B} a \mathrm{P}$ and metabolites over time in the PBTK model compartments.

In general, kinetics in organ $i$ is described by the equation:

$\frac{d\left(C_{i}\right)}{d t} \times V_{i}=Q_{i} \times\left(c_{b}-\frac{C_{i}}{P_{i}}\right)$

with $C_{i}, V_{i} Q_{i}$ and $P_{i}$ respectively the concentration, the volume, the blood flow and the partition coefficient with blood of organ $i$, and $c_{b}$ the concentration in blood (venous for lung, arterial for the other organs).

For adipose tissues, the kinetics of $\mathrm{B} a \mathrm{P}$ in blood and in tissues is described by:

$\frac{d\left(C_{b f}\right)}{d t} V_{b f}=Q_{f} \times\left(c_{b}-c_{b f}\right)-D \times\left(c_{b f}-\frac{C_{f}}{P_{f}}\right)$

$\frac{d\left(C_{f}\right)}{d t} V_{f}=D \times\left(c_{b f}-\frac{C_{f}}{P_{f}}\right)$

For liver, the kinetics of $\mathrm{B} a \mathrm{P}$ is described by:

$\frac{d\left(C_{h}\right)}{d t} V_{h}=Q_{h}\left(c_{b}-\frac{C_{h}}{P_{h}}\right)-\frac{V_{\max }}{P_{h}}\left(\frac{C_{h}}{C_{h}+K_{m}}\right)$

and the kinetics of metabolites by:

$\frac{d\left(C_{M h}\right)}{d t} V_{h}=Q_{h}\left(c_{M b}-\frac{C_{M h}}{P_{h}}\right)+\frac{V_{\max }}{P_{h}}\left(\frac{C_{h}}{C_{h}+K_{m}}\right)-K_{\text {elim }} C_{M h}$

\subsection{Calibration of the PBTK model}

The parameters we estimated were the partition coefficients between blood and lung, liver, and slowly perfused tissues for $\mathrm{B} a \mathrm{P}$, the partition coefficients between blood and lung, liver, and other tissues for metabolites, and the metabolite elimination rate. Parameters were estimated through maximum likelihood methods. We fitted simultaneously the two datasets with common parameters, with the exception of liver partition coefficient which had to be differentiated to fit liver concentration data in both studies. The measurement errors were 
assumed to be independent and log-normally distributed, with a geometric mean equal to the PBTK model predictions and a geometric standard deviation (GSD) of 1.1 (approximately $10 \%$ error) for $\mathrm{B} a \mathrm{P}$, and 1.2 for metabolites. We chose a higher GSD for metabolites compared to parent compound because the concentrations were calculated as the difference between two measured concentrations (total concentration minus $\mathrm{B} a \mathrm{P}$ concentration). Data likelihoods were therefore given by:

$$
\log (Y) \sim N\left(\log (F(X, \theta)), \sigma_{c}\right)
$$

where the function $F(X, \theta)$ corresponds to a PBTK model with input $\mathrm{X}$ and parameters $\theta$, and $\sigma_{c}$ is equal to either 1.1 or 1.2. Parameters estimation and building of confidence intervals were performed using the MCSim software (Bois and Maszle, 1997).

\section{Results}

\subsection{PBTK modeling}

The fits of the PBTK model to Weyand and Bevan (1986) data are presented in Figure 3 for blood, lung, liver and intestines. The fits of the model to the Shlede et al. (1970) data are presented in Figure 4 for blood, lung, liver and adipose tissues. Only 2 out of the 52 predictions differ from the measured values by a factor higher than 2. Parameters' estimates are given in Table 1. Confidence curves relative to the estimated parameters are shown in Figures 3 and 4.

The same parameters were used for both studies, with the exception of liver partition which was more than 5 times higher for Weyand and Bevan data compared to Shlede data. We found high partition coefficient values for liver and lung, when compared to the values usually used in risk assessment based on QSAR modeling (Chiang and Liao, 2006). In contrast, coefficients for slowly perfused tissues were within expected ranges based on QSAR or dialysis experiments (Chiang and Liao, 2006 ; Moir, 1999) and predicted hepatic clearance was well accounted for based on the in vitro study by Wiersma and Roth (1983). For all tissues, metabolites had lower partition coefficients than $\mathrm{B} a \mathrm{P}$.

\subsection{In vitro dose-response model for the Gene expression}


Figure 5 presents the results of IL-1 $\beta$ and NCF1 mRNA induction in response to various increasing concentrations of $\mathrm{B} a \mathrm{P}$ in primary human macrophages. IL-1 $\beta$ and $\mathrm{NCF} 1$ inductions were significantly greater than 1 for respectively concentrations over 0.12 and $0.04 \mu \mathrm{M}$ (multirange Dunnett's t test, $p<0.05$ ). The fit with the Hill model provided the following estimates for IL-1 $\beta$ with $95 \%$ confidence intervals: $n=1.4[1.16 ; 1.86], E_{\max }=126[42 ; 166]$, $c_{50}=5.6[2.7 ; 9.3]$. We obtained the following estimates for NCF1 with $95 \%$ confidence intervals: $n=0.65[0.55 ; 0.9], E_{\max }=25[15 ; 27], c_{50}=13[5 ; 18]$.

\subsection{Prediction of in vivo gene expression based on TK/TD modeling}

The PBTK model was used to predict the toxicokinetic profile of $\mathrm{B} a \mathrm{P}$ in lungs during $24 \mathrm{~h}$ after an intratracheal instillation of $3 \mathrm{mg} / \mathrm{kg}$. Since two different values were estimated for the partition coefficient liver:blood from the two toxicokinetic datasets, both estimates were used to run the model. No significant difference was observed on the predicted lungs concentrations. Figure 6 presents the predicted internal dosimetry in lungs for 24 hours. Since only little information was available to determine the entity responsible of the modulation of the gene expression, three model outputs were chosen: the concentration in lungs at the time of the appearance of the effect and the mean concentration in lungs during the last hour or the last four hours before the appearance of the effect. The time ranges of one or four hours before the appearance of the effect are supported by previous results. Pinel-Marie et al. (2009) showed that 1 to 4 hours are necessary to induce a change in the gene expression after an in vitro exposure of macrophages to $2 \mu \mathrm{M}$ of $\mathrm{BaP}$. Table 2 presents the internal concentrations in lungs with the respective prediction of the gene expressions obtained with the dose-response model. We observed that these predicted gene expressions are quite similar for the 3 concentrations in lungs (3.3 to 3.6-fold for NCF1, and 3.8 to 4.9-fold for IL-1 $\beta$ ).

These predictions were compared to the values observed in the in vivo studies in rats. In vivo, a mean induction of 2.39-fold for NCF1 and 3.72-fold for IL-1 $\beta$ was observed in alveolar macrophages from rats treated by intratracheal instillation of $\mathrm{B} a \mathrm{P}$ when compared to alveolar macrophages from untreated rats. For the gene IL-1 $\beta$, a good concordance is obtained between the predictions of the PBTK model linked to the dose-response model derived with in vitro data and the actual values measured in rats. For the gene NCF1, the modelling approach tends to over-predict slightly the gene induction. The dose-response model was used 
in reverse to estimate the concentration in lungs that would provide the observed in vivo inductions. A concentration of $0.36 \mu \mathrm{M}$ was predicted for IL- $1 \beta$ and $0.17 \mu \mathrm{M}$ for NCF1.

\section{Discussion}

\subsection{PBTK modeling}

We could calibrate a PBTK model based on intratracheal instillation and intravenous administration, with a quality of fit which has not been reached by previous attempts to build a PBTK model for $\mathrm{B} a \mathrm{P}$.

Contrary to Moir (1999), we were able to describe the data with our model using the metabolic parameters estimated in vitro (Wiersma and Roth, 1983). Usually, it is accepted that $K_{m}$ values does not change between in vitro and in vivo situations, but that $V_{\max }$ value has to be adjusted (Haddad et al., 1998). As in the model by Roth and Vinegar (1990), such an adjustment was not necessary. Metabolism in the lungs is likely to occur, but was neglected in our model. We showed that the introduction of pulmonary clearance, with parameters from Wiersma and Roth (1983), would not have affected our results (less than 5\% difference in the predictions for lung concentration). Previous results with intravenous administration confirm this poor influence of lung metabolism. Intravenous administration and intratracheal instillation lead to close kinetics, as shown by Weyand and Bevan (1986) because of the high rate of exchange between blood and lungs. In their study of intravenous administration of 29.5 $\mu \mathrm{g} / \mathrm{kg} \mathrm{BaP}$, which is close to the doses used in the studies we analyzed, Roth and Vinegar (1990) showed that the amount of $\mathrm{B} a \mathrm{P}$ metabolized by the lung compared to the total amount of metabolized $\mathrm{B} a \mathrm{P}$ is only $3.5 \%$. In their study, lung metabolism was substantial only when animals had been pretreated with cytochrome P450 monooxygenase inducer 3methylcholanthrene in agreement with previous studies (Seifried, 1977).

We estimated partition coefficients values between blood and lung which are far above those previously used for PAH risk assessment. Metabolizing tissues contain macromolecules, like AhR and other proteins, to which PAH compounds may specifically bind (Haddad et al., 1998). Consequently, the algorithm by Poulin and Krishnan (1995) used by Chiang and Liao (2006), which is based on the neutral lipid, phospholipid and water contents of blood and organs, may not be appropriate to estimate PAH partition coefficients for lung and liver.

Liver partition estimate was more than 5 times higher for Weyand and Bevan data, corresponding to the study with the lowest exposure dose, compared to Shlede data. This 
difference could be due to a sequestration mechanism (AhR) at low concentrations which is saturated for higher concentrations or it could be due to differences in $\mathrm{B} a \mathrm{P}$ measurement methods in liver between the two studies. This difference is just related to liver concentration, but did not affect hepatic clearance which remained the same for the two studies, as liver concentrations were far below Michaelis metabolism constant in the liver.

We integrated $\mathrm{B} a \mathrm{P}$ metabolites in our model, but did not distinguish between the different compounds. Weyand and Bevan showed that the repartition between the metabolites in lung, liver and intestine was relatively constant from 60 to $360 \mathrm{~min}$, and we consequently believe that the modeling of the kinetics of $\mathrm{B} a \mathrm{P}$ metabolites using common parameters is still realistic.

\subsection{Gene expression data}

We used our model to predict lung concentration after intratracheal instillation for a dose of $3 \mathrm{mg} / \mathrm{kg} \mathrm{BaP}$ and obtained a good correlation between gene expression responses in human macrophages in vitro exposed to $\mathrm{B} a \mathrm{P}$ and in rat counterparts in vivo exposed to the PAHs. This suggests that human and rat macrophages in different tissues provide comparable response to $\mathrm{B} a \mathrm{P}$ exposure, at least relative to mRNA induction, and that our PBTK model is able to link in vitro and in vivo responses through the calculation of macrophage exposure in rat.

We related gene expression either to the concentration at a given time or to the mean of concentration during the last one or four hours. There was little difference relative to the prediction in vivo even if the one related directly to the mean concentration at a given time provided the closest prediction compared to actual values. It is important to note that the mean value or the concentration value is not necessarily the right endpoint when relating in vitro and in vivo toxicity. For instance, Verwei et al. (2006) referred to the maximum internal concentration when succeeding to relate developmental effects assessed in vitro and in vivo assuming that such effects occur as soon as a threshold is exceeded. In our study, we tried alternatives such as mean lung concentration over the whole exposure interval or highest lung concentration, but the resulting predictions for genes expression would have largely exceeded the measurements.

Our results are promising for we have developed a predictive tool able to transpose at a systemic level dose-response obtained quickly on cells. In particular, assessing the response 
of cells exposed to complex mixtures including PAH compounds would be much easier in vitro than in vivo.

\section{Conflict of interest}

This paper has no conflict of interest.

\section{Acknowledgements}

This study was founded by the French Ministry in charge of Ecology and Sustainable Development, within the framework of Programmes 189 and 190, and by the European Commission 6th Framework Program, Priority 6 (Global change and ecosystems), project 2FUN [contract \#036976]. We also would like to thank an anonymous reviewer, Rémy Beaudouin and Cleo Tebby for their careful reading of the manuscript.

\section{References}

Bois, F., Maszle, D., 1997. MCSim: A simulation program, Journal of Statistical Software, 2(9):http://www.stat.ucla.edu/journals/jss/v02/i09.

Chiang, K.C., Liao, C.M., 2006. Heavy incense burning in temples promotes exposure risk from airborne PMs and carcinogenic PAHs. Sci. Total Environ. 372, 64-75.

Davies, B., Morris, T., 1993. Physiological parameters in laboratory animals and humans. Pharm. Res. 10, 1093-1096.

Haddad, S., Withey, J., Laparé, S., Law, F., Krishnan, K., 1998. Physiologically-based pharmacokinetic modeling of pyrene in the rat. Environ. Toxicol. Pharmacol. 5, 245-255.

Krewski, D., Acosta, D., Andersen, M., Anderson, H., Bailar, J.C., Boekelheide, K., Brent, R., Charnley, G., Cheung, V.G., Green, S., Kelsey, K.T., Kerkvliet, N.I., Li, A.A., McCray, L., Meyer, O., Patterson, R.D., Pennie, W., Scala, R.A., Solomon, G.M., Stephens, M., Yager, J., Zeise, L., 2010. Toxicity testing in the $21^{\text {st }}$ century: a vision and a strategy. J. Toxicol. Environ. Health B Crit. Rev. 13, 51-138.

Lecureur, V., Ferrec, E. L., N'Diaye, M., Vee, M. L., Gardyn, C., Gilot, D., Fardel, O., 2005. ERK-dependent induction of TNFalpha expression by the environmental contaminant benzo(a)pyrene in primary human macrophages. FEBS Lett. 579, 1904-1910.

Moir, D., 1999. Physiological modeling of benzo(a)pyrene pharmacokinetics in the rat. In Toxicity assessment alternatives: methods, issues, opportunities (H. Salem, and S.A. Katz, Eds.), pp. 79-95. Humana Press Inc., Totowa, NJ. 
N'Diaye, M., Le Ferrec, E., Lagadic-Gossmann, D., Corre, S., Gilot, D., Lecureur, V., Monteiro, P., Rauch, C., Galibert, M. D., Fardel, O., 2006. Aryl hydrocarbon receptor- and calcium-dependent induction of the chemokine CCL1 by the environmental contaminant benzo[a]pyrene. J. Biol. Chem. 281,19906-19915.

Pinel-Marie, M.-L., Sparfel, L., Desmots, S., Fardel, O., 2009. Aryl hydrocarbon receptordependent induction of the NADPH oxidase subunit NCF1/p47phox expression leading to priming of human macrophage oxidative burst. Free Radic. Biol. Med. 47, 825-834.

Podechard, N., Lecureur, V., Le Ferrec, E., Guenon, I., Sparfel, L., Gilot, D., Gordon, J. R., Lagente, V., Fardel, O., 2008. Interleukin-8 induction by the environmental contaminant benzo $(a)$ pyrene is aryl hydrocarbon receptor-dependent and leads to lung inflammation. Toxicol. Lett. 177, 130-137.

Poulin, P., Krishnan, K., 1995. An algorithm for predicting tissue:blood partition coefficients of organic chemicals from n-octanol:water partition coefficient data. J. Toxicol. Environ. Health 46, 101-113.

Pufulete, M., Battershill, J., Boobis, A., Fielder, R. 2004. Approaches to carcinogenic risk assessment for polycyclic aromatic hydrocarbons: a UK perspective. Regul. Toxicol. Pharmacol. 40, 54-66.

R Development Core Team, 2008. R: A language and environment for statistical computing. R Foundation for Statistical Computing, Vienna, Austria. ISBN 3-900051-07-0, URL http://www.R-project.org.

Roth, R.A., Vinegar, A., 1990. Action by the lungs on circulating xenobiotic agents, with a case study of physiologically based pharmacokinetic modeling of benzo( $a$ )pyrene disposition. Pharmac. Ther. 48, 143-155.

Schlede, E., Kuntzman, R., Haber, S., Conney, A.H., 1970. Effect of enzyme induction on the metabolism and tissue distribution of benzo(a)pyrene. Cancer Res. 30, 2893-2897.

Seifried, H.E., Birkett, D.J., Levin, W., Lu, A.Y.H., Conney, A.H., Jerina D.M. 1977. Metabolism of benzo[a]pyrene: Effect of 3-methylcholanthrene pretreatment on metabolism by microsomes from lungs of genetically "responsive" and "nonresponsive" mice. Arch. Biochem. Biophys. 178, 253-263.

Slotkin, T.A., Seidler, F.J., 2009. Benzo[a]pyrene impairs neurodifferentiation in PC12 cells. Brain Res. Bull. 80, 17-21.

Sorensen, M., Autrup, H., Moller, P., Hertel, O., Jensen, S. S., Vinzents, P., Knudsen, L. E., Loft, S., 2003. Linking exposure to environmental pollutants with biological effects. Mutat. Res. 544, 255-271.

Sparfel, L., Pinel-Marie, M.-L., Boize, M., Koscielny, S., Desmots, S., Péry A., Fardel, O., 2010. Transcriptional Signature of Human Macrophages Exposed to the Environmental Contaminant Benzo(a)pyrene. Toxicol. Sci. 114, 247-259. 
Van Grevenynghe, J., Sparfel, L., Le Vee, M., Gilot, D., Drenou, B., Fauchet, R., Fardel, O., 2004. Cytochrome P450-dependent toxicity of environmental polycyclic aromatic hydrocarbons towards human macrophages. Biochem. Biophys. Res. Commun. 317, 70816.

Varma, R., Hector, S., Greco, W.R., Clark, K., Hawthorn, L., Porter, C., Pendyala, L., 2007. Platinum drug effects on the expression of genes in the polyamine pathway: time-course and concentration-effect analysis based on Affymetrix gene expression profiling of A2780 ovarian carcinoma cells. Cancer Chemother. Pharmacol. 59, 711-723.

Verwei, M., van Burgsteden, J.A., Krul, C.A.M., van de Sandt, J.J.M., Freidig, A.P., 2006. Prediction of in vivo embryotoxicity effect levels with a combination of in vitro studies and PBPK modelling. Toxicol. Lett. 165, 79-87.

Vyskocil, A., Viau, C., Camus, M., 2004. Risk assessment of lung cancer related to environmental PAH pollution sources. Hum. Exp. Toxicol. 23, 115-127.

Weyand, E.H., Bevan, D.R., 1986. Benzo(a)pyrene disposition and metabolism in rats following intratracheal instillation. Cancer Res. 46, 5655-5661.

Wiersma, D.A., Roth, R.A. 1983. The prediction of benzo( $a)$ pyrene clearance by rat liver and lung from enzyme kinetic data. Mol. Pharmacol. 24, 300-308.

Zeilmaker, M.J., van Eijkeren J.C.H., Olling M. 1999. A PBPK-model for B $(a) \mathrm{P}$ in the rat relating dose and liver DNA-adduct level. RIVM report 658603008 . Bilthoven, The Netherlands. 


\section{Table 1}

Parameters of the PBTK model for Sprague Dawley rats $(0.25 \mathrm{~kg})$ exposed to $\mathrm{B} a \mathrm{P}$. Blood flows were calculated based on cardiac output in Davies and Morris (1993) and percentages of cardiac output in Haddad et al. (1998). Partition coefficient for richly perfused tissues was taken from measurements by Moir (1999). Partition coefficient for adipose tissues was taken as the mean experimental measurement by Zeilmaker et al. (1999). Michaelis constant and maximum metabolism rate for liver came from an in vitro study (Wiersma and Roth, 1983) and were extrapolated to rats by using the allometric scaling for interspecies extrapolation (Haddad et al., 1998). Diffusion coefficient in adipose tissues was assumed to be the same value as used by Haddad et al. (1998) for pyrene.

\begin{tabular}{llll}
\hline Volume of venous blood & $V v b$ & $10 \mathrm{~mL}$ & Haddad et al, 1998 \\
\hline Volume of arterial blood & $V a b$ & $5 \mathrm{~mL}$ & Haddad et al., 1998 \\
\hline Volume of fat & $V f$ & $22.5 \mathrm{~mL}$ & Haddad et al, 1998 \\
\hline Volume of blood in fat & $V b f$ & $0.15 \mathrm{~mL}$ & Haddad et al, 1998 \\
\hline Volume of slowly perfused tissues & $V s$ & $167.5 \mathrm{~mL}$ & Haddad et al., 1998 \\
\hline Volume of richly perfused tissues & $V r$ & $9.5 \mathrm{~mL}$ & Haddad et al, 1998 \\
\hline Volume of lung & $V l$ & $3 \mathrm{~mL}$ & Haddad et al, 1998 \\
\hline Volume of liver & $V h$ & $10 \mathrm{~mL}$ & Haddad et al, 1998 \\
\hline Adipose blood flow & $Q f$ & $6.7 \mathrm{~mL} / \mathrm{min}$ & Haddad et al, 1998 \\
\hline Slowly perfused blood flow & $Q s$ & $11.1 \mathrm{~mL} / \mathrm{min}$ & Haddad et al, 1998 \\
\hline Richly perfused blood flow & $Q r$ & $37.8 \mathrm{~mL} / \mathrm{min}$ & Haddad et al, 1998 \\
\hline Total blood flow (Cardiac output) & $Q c$ & $74 \mathrm{~mL} / \mathrm{min}$ & Davies and Morris, 1993 \\
\hline Liver blood flow & $Q h$ & $18.4 \mathrm{~mL} / \mathrm{min}$ & Haddad et al, 1998 \\
\hline BaP PC fat over blood & $P f$ & 50 & Zeilmaker et al., 1999 \\
\hline BaP PC slowly perfused tissues over blood & $P s$ & 3.5 & Estimated \\
\hline BaP PC richly perfused tissues over blood & $P r$ & 1.6 & Moir, 1999 \\
\hline BaP PC lung over blood & $P l$ & 88 & Estimated \\
\hline BaP PC liver over blood & $P h$ & 134 & Estimated from Weyand \\
& & & and Bevan data \\
& & 25 & Estimated from Schlede \\
& & & et al data. \\
\hline Metabolites PC lung over blood & $P_{M} l$ & 25.7 & Estimated \\
\hline Metabolites PC liver over blood & $P_{M} h$ & 7.9 & Estimated \\
\hline Metabolites PC other tissues over blood & $P_{M} O$ & 1.7 & Estimated \\
\hline Metabolites elimination rate & $K e l i m$ & $0.321 \mathrm{~mL} / \mathrm{min}$ & Estimated \\
\hline Liver maximum metabolism rate & $V m a x$ & $0.087 \mathrm{mg} / \mathrm{min}$ & Wiersma and Roth, 1983 \\
\hline Liver metabolism Michaelis constant & $K m$ & $0.00139 \mathrm{mg} / \mathrm{mL}$ & Wiersma and Roth, 1983 \\
\hline Diffusion coefficient in adipose tissues & $D$ & $1.7 \mathrm{~mL} / \mathrm{min}$ & Haddad et al, 1998 \\
\hline & & & \\
\hline
\end{tabular}




\section{Table 2}

Predicted mean value and confidence interval (between brackets) for $\mathrm{B} a \mathrm{P}$ lung concentration for a selected period of time and corresponding IL-1 $\beta$ and NCF1 inductions. The actual induction value is also provided.

\begin{tabular}{llll}
\hline & Lung concentration $(\mu \mathrm{M})$ & IL-1 $\beta$ induction & NCF1 induction \\
\hline Concentration at 24h & $0.37[0.34 ; 0.4]$ & $3.3[3.2 ; 3.4]$ & $3.8[3.6 ; 4.3]$ \\
\hline $\begin{array}{l}\text { Mean concentration } \\
\text { between 23h and 24h }\end{array}$ & $0.42[0.39 ; 0.45]$ & $3.4[3.3 ; 3.5]$ & $4.3[4.2 ; 5]$ \\
\hline $\begin{array}{l}\text { Mean concentration } \\
\text { between 20h and 24h }\end{array}$ & $0.47[0.43 ; 0.51]$ & $3.6[3.4 ; 3.7]$ & $4.9[4.7 ; 5.7]$ \\
\hline Measured value & & 2.4 & 3.7 \\
\hline
\end{tabular}




\section{Figure legends}

Fig. 1. Schematic presentation of the methodology used to compare predicted and actual gene expression in rodents exposed to $\mathrm{B} a \mathrm{P}$.

Fig. 2. Schematic presentation of the PBTK model used to describe the kinetics of $\mathrm{B} a \mathrm{P}$ and its metabolites. Symbols are presented in Table 1.

Fig. 3. $\mathrm{B} a \mathrm{P}$ and metabolites kinetics in blood, lung, liver and intestine (data points are mean values from Weyand and Bevan, and fits with 95\% confidence intervals).

Fig. 4. $\mathrm{B} a \mathrm{P}$ kinetics in blood, lung, liver and fat (data points are mean values from Schlede et $a l$, and fits with $95 \%$ confidence intervals).

Fig. 5. IL-1 $\beta$ and NCF1 mRNA induction in response to $\mathrm{B} a \mathrm{P}$ treatment in primary human macrophages. Data are expressed relative to mRNA levels found in untreated cells, arbitrarily set at a value of 1 . The fit with the Hill model is presented.

Fig. 6. Time course of lung $\mathrm{B} a \mathrm{P}$ concentration in rats after intratracheal instillation of 3 $\mathrm{mg} / \mathrm{kg}$, as predicted by the PBTK model. 